\title{
The Nuclear and DNA-Associated Molecular Chaperone Network
}

\author{
Zlata Gvozdenov, ${ }^{1,2}$ Janhavi Kolhe, ${ }^{1}$ and Brian C. Freeman ${ }^{1}$ \\ ${ }^{1}$ Department of Cell and Developmental Biology, University of Illinois, Urbana-Champaign, \\ Urbana, Illinois 61801 \\ ${ }^{2}$ Department Chemie, Technische Universität München, Garching 85748, Germany \\ Correspondence: bfree@illinois.edu
}

Maintenance of a healthy and functional proteome in all cellular compartments is critical to cell and organismal homeostasis. Yet, our understanding of the proteostasis process within the nucleus is limited. Here, we discuss the identified roles of the major molecular chaperones Hsp90, Hsp70, and Hsp60 with client proteins working in diverse DNA-associated pathways. The unique challenges facing proteins in the nucleus are considered as well as the conserved features of the molecular chaperone system in facilitating DNA-linked processes. As nuclear protein inclusions are a common feature of protein-aggregation diseases (e.g., neurodegeneration), a better understanding of nuclear proteostasis is warranted.

M olecular chaperones facilitate the life cycle of most, if not all, proteins from promoting nascent chain folding to modulating the activities/stabilities of seemingly native proteins to guiding the proper disposal of worn/damaged factors. Although the coterie of proteins forming a molecular chaperone system share little to no structural features, together these diverse constituents serve the critical function of maintaining cellular and organismal protein homeostasis (i.e., proteostasis). Significantly, breakdown in the proteostasis process correlates with numerous diseases including neurodegeneration, type II diabetes, and heart failure (Balch et al. 2008; Powers et al. 2009). Although defects in proteostasis are typically studied in the context of the cytosol, as nascent polypeptide folding occurs in this compartment, biopsies from patients suffer- ing from aggregation diseases (e.g., neurodegeneration) (see Dobson et al. 2019; Jayaraj et al. 2019) indicate that protein inclusions in the nucleus are common thereby demonstrating the importance of understanding how proteostasis is coordinated in the nucleoplasm (Metuzals et al. 1988; Hackam et al. 1999). Yet, our understanding of nuclear proteostasis is quite limited. Here, we will describe how the intersection between molecular chaperones and nuclear- and/ or DNA-associated proteins facilitates an active proteome.

Although the nuclear compartment is not encumbered by the many challenges of nascent polypeptide folding, the environment at or near a genome is nonetheless confronted by trials to protein health and function (Echtenkamp and Freeman 2014). The most apparent need is for

Editors: Richard I. Morimoto, F. Ulrich Hartl, and Jeffery W. Kelly

Additional Perspectives on Protein Homeostasis available at www.cshperspectives.org

Copyright (C) 2019 Cold Spring Harbor Laboratory Press; all rights reserved; doi: 10.1101/cshperspect.a034009

Cite this article as Cold Spring Harb Perspect Biol 2019;11:a034009 


\section{Z. Gvozdenov et al.}

the cyclical building and dismantling of macromolecular structures that repetitively engage a common ligand (i.e., DNA) with nanomolar affinities yet must retain a dynamic interaction with the DNA as well as each other (Mueller et al. 2013). Basically, genomic pathways typically enlist a series of macromolecular complexes to perform a singular end point task that is constantly tuned by the current biological status of a cell. For example, the initiation of RNA synthesis in eukaryotes requires the cohesive actions of multiple transcription factors that nucleate a series of coactivators, including chromatin remodelers, histone acetyltransferases, histone methyltransferases, mediators, general transcription factors, and core RNA polymerase subunits to produce the requisite level of each and every gene transcript (Hager et al. 2009). As the physiological needs of a cell often vary, the production of RNA must in turn be rapidly modified. Furthering the complexity is the limited pool of each type of coactivator (e.g., humans have 10 basic chromatin remodelers), which necessitates a means to disperse these complexes across the genomic landscape.

To overcome these obstacles, transcription proteins often persist in modular states with the components moving with near diffusion constants within nuclei, thereby enabling on-call assembly of the necessary subunits at any given DNA site (Echtenkamp and Freeman 2014). Hence, the proper control of the $\sim 20,000 \mathrm{hu}-$ man genes requires an effective system for continuously assembling and disassembling the multitude of enlisted macromolecular DNAassociated structures. As these factors are redundantly used across the genome, the physical well-being of each protein also must be checked and repaired, if needed. We suggest molecular chaperones have important roles in the upkeep of DNA-associated pathways and nuclear proteostasis. As the maintenance of any system is more efficient than de novo synthesis and destruction, a continuous chaperone action with mature proteins would be beneficial for perpetuating the active nuclear protein landscape. In this scenario, redundant chaperone-client interactions perpetuate a continuous assembly/ disassembly of macromolecular structures along the genome while also monitoring for damaged proteins. If the worn factors can be fixed then the chaperones will facilitate the correction, if not then the chaperones will guide the destruction of the damaged client thereby ensuring a healthy proteome.

Molecular chaperones were functionally revealed using clever genetic screens designed to identify the host factors supporting the propagation of $\lambda$ phage (Georgopoulos 2006). The isolated mutations that hit on molecular chaperones impaired either $\lambda$ head assembly or replication of the phage DNA. The mutants blocking head assembly were found to be in the host molecular chaperone GroEL and GroES (Georgopoulos et al. 1973; Sternberg 1973): the Gro being derived from the inability of these mutants to grow $\lambda$ phage, $\mathrm{E}$ coming from the name of the major $\lambda$ head protein $\mathrm{E}$, and $\mathrm{L} / \mathrm{S}$ reflecting the larger ( $60 \mathrm{kDa}$ GroEL) and smaller (10 $\mathrm{kDa}$ GroES) host protein products (Tilly et al. 1981). The host factors supporting $\lambda$ DNA replication were found to be DnaK and DnaJ (Yochem et al. 1978), which encode the Escherichia coli homologs of Hsp70 and Hsp40, respectively, along with GrpE (GroP-like gene E) (Saito and Uchida 1978). Although the involvement of the Hsp70 system with DNA events is clear right from the beginning, the association between GroEL and DNA pathways are more tenuous. Yet, numerous observations suggest GroEL homologs, along with the third major molecular chaperone system Hsp90, have critical roles within the nuclei of eukaryotes as well as DNA-associated pathways in prokaryotes as will be discussed below.

\section{HSP70 MOLECULAR CHAPERONES}

Ferruccio Ritossa provided the first evidence that cells react to a proteostasis imbalance when he reported that either superphysiological temperatures or the metabolic uncoupler 2,4-dinitrophenol (DNP) triggered chromosomal puffs in Drosophila melanogaster salivary glands ( $\mathrm{Ri}-$ tossa 1962). Further work revealed that the puffs were sites of gene transcription leading to the elevated production of heat shock proteins (HSPs), including Hsp70, Hsp90, and Hsp60 
(Tissiéres et al. 1974; Ashburner and Bonner 1979). Through the concerted efforts of numerous laboratories, the HSPs would eventually be connected to DnaK and GroEL as well as being shown to be the primary molecular chaperones of all living cells (Kim et al. 2013). In many respects, research on Hsp70 provided the basis for our understanding of what a molecular chaperone is capable of doing because Hsp70s were shown to mediate nascent protein folding, macromolecular assembly/disassembly, protein transport, protein degradation, etc. (Mayer and Bukau 2005). Yet, it is notable that the initial discovery of an Hsp70 (DnaK) emanated from its ability to disassemble a $\lambda$ phage proteinDNA complex (Georgopoulos 2006).

At the $\lambda$ origin of replication 2 phage proteins $(\mathrm{O}$ and $\mathrm{P})$ along with a host factor (DnaB helicase) form the preprimosomal complex that is disassembled by DnaK in conjunction with its cochaperones DnaJ and GrpE (Zylicz 1993). In brief, these chaperones trigger the release of $\mathrm{P}$, thereby freeing DnaB to unwind the DNA and initiate replication (Hoffmann et al. 1992). In addition to being detrimental to the $\lambda$ life cycle, mutations in dnaK impact DNA replication and transcription of the host cell as well as causing a thermosensitivity phenotype (Itikawa and Ryu 1979; Paek and Walker 1987; Sakakibara 1988). Further analysis of $d n a K$ mutants revealed an inability to properly segregate host chromosomes or maintain plasmids (Bukau and Walker 1989). Minimally, DnaK supports chromosome and plasmid replication by establishing an active form of the initiator protein DnaA, including its release from phospholipids (Hwang et al. 1990; Wickner et al. 1991). The capacity of DnaK to foster the DNA-binding activities of proteins might be a general feature because it also activates $\operatorname{RepA}$, which is needed for replication of the P1 plasmid (Wickner et al. 1991). Whether these examples represent the folding capacity of DnaK or whether DnaK plays an active regulatory role with mature DNA-binding proteins has not been shown.

An influence of DnaK in both general and select transcription pathways also has been described. For instance, DnaK copurifies with bacterial RNA polymerase (Skelly et al. 1988).
At the least, the DnaK-RNA polymerase interaction protects the enzyme under stress conditions and can reactivate the polymerase if aggregated during heat treatment (Skowyra et al. 1990). Significantly, the ability of DnaK to disaggregate misfolded RNA polymerase was one of the first lines of evidence that an Hsp70 homolog could function as a molecular chaperone in terms of protein refolding. Yet, it is unlikely that the protective role that DnaK serves with RNA polymerase accounts for its interaction with RNA polymerase under physiological conditions because the chaperone is binding to the native complex. Yet, any additional role(s) DnaK has with RNA polymerase have not been revealed. However, the mechanism by which DnaK modulates the heat shock transcription response was elucidated.

In most bacteria, DnaK is the primary inhibitor of the heat shock sigma factor $\left(\sigma^{32}\right)$ or RNA polymerase $\mathrm{H}(\mathrm{RpoH})$ protein under normal physiological conditions (Arsène et al. 2000). In brief, DnaK directly binds $\sigma^{32}$, along with DnaJ, and GrpE, targeting $\sigma^{32}$ for degradation by the $\mathrm{FtsH}$ protease until there is an increased demand for general chaperone activity within the cell (e.g., stress-induced accumulation of nonnative proteins) that titrates the chaperones away from $\sigma^{32}$. The freed $\sigma^{32}$ readily associates with the core RNA polymerase complex to mount a heat shock response gene program. Competition with the housekeeping sigma factor $\left(\sigma^{70}\right)$ is limited by a heat-induced aggregation of $\sigma^{70}$. Intriguingly, as stress conditions dissipate, the now overabundant HSPs target both $\sigma^{32}$ and $\sigma^{70}$. Reactivating $\sigma^{70}$ for interactions with core RNA polymerase thereby returns to a normal housekeeping gene program while also destabilizing $\sigma^{32}$ and directing it once again to the FtsH degradation cycle. Essentially, DnaK serves as the focal point of an autoregulatory loop that maintains proteostasis within most prokaryotes by controlling the key transcription factors that mediate normal and stress gene programs on a global scale.

Besides DNA replication and RNA transcription, DnaK also supports the DNA repair process. Significantly, dnaK mutants show sensitivity to ultraviolet (UV) irradiation, are 
Z. Gvozdenov et al.

sensitive to replication fork damage, and have a constitutive SOS response (Petit et al. 1994; Zou et al. 1998; Goldfless et al. 2006). Nominally, DnaK maintains the activity of the repair proteins UvrA (endonuclease subunit) and UmuC (DNA polymerase V subunit). Curiously, UmuC needs sequential chaperone action in which DnaK establishes its DNA-binding activity and the GroEL chaperonin fosters DNA lesion bypass by DNA polymerase V (Petit et al. 1994). Yet, for DNA polymerase III, it is DnaK that rearranges the replisome to promote the repair of damaged DNA occurring during replication template switching (Goldfless et al. 2006). Although it was initially suggested that DnaK's contribution to the DNA repair process was through classic chaperone folding activity, the influence of DnaK on the DNAbound polymerase III replisome complex indicates that the chaperone is able to have downstream regulatory roles with a client (Goldfless et al. 2006). In light of this finding, it is perhaps worth revisiting whether DnaK is commonly used to influence mature protein/protein complexes.

Importantly, the relationships between DnaK and proteins working along the genome are conserved features with eukaryotic Hsp70s. For instance, human Hsp70 promotes DNA replication of papillomavirus and herpes simplex virus type I (Liu et al. 1998; Tanguy Le Gac and Boehmer 2002). In both cases, Hsp70 fosters the interaction of an initiator protein with its cognate origin of DNA replication, which is analogous to the impact of DnaK with DnaA or RepA. Perhaps notably, the impact of Hsp70 on the herpes simplex virus initiator protein UL9 is select for DNA replication events, as Hsp70 had no apparent effect on origin-independent roles of UL9 (Tanguy Le Gac and Boehmer 2002). Furthermore, mammalian Hsp70s appear to form part of an autoregulatory inhibitory loop for the heat shock response because Hsp70 interacts with DNA-bound heatshock factor 1 (HSF1) and represses the activity of HSF1 (Abravaya et al. 1992; Shi et al. 1998). Hence, Hsp70 roles in both viral DNA replication and control of the heat shock response are conserved.
Early studies on eukaryotic Hsp70s showed that stress conditions (i.e., heat and anoxia) triggered a nuclear enrichment of this chaperone, including localization to the nucleoli and chromatin (Arrigo et al. 1980; Velazquez and Lindquist 1984). It was suggested that the nuclear localization of Hsp70 protected labile proteins especially the ribonucleoprotein (RNP) complexes within the nucleoli because overexpression of Hsp70 accelerated nucleolar recovery after a heat shock (Pelham 1984). Hsp70 seems to commonly promote the construction of protein-RNA complexes, in conjunction with Hsp90, because these chaperones facilitate the assembly of divergent RNP structures, including telomerase, hepadnavirus reverse transcriptase, and RNA-induced silencing complexes (RISCs) (Hu and Anselmo 2000; Forsythe et al. 2001; Iwasaki et al. 2010, 2015). Yet, Hsp70 interacts with assembled heterogeneous nuclear RNPs (hnRNPs) under both ambient and heat shock temperatures suggesting a regulatory role with the complexes in addition to the protective one (Kloetzel and Bautz 1983), whereas Hsp90 remains associated with telomerase to modulate this complex postassembly (Forsythe et al. 2001; Toogun et al. 2008). Intriguingly, the protein interactions formed with Hsp70 in the nucleus vary with the cell cycle, suggesting that the nuclear clients of Hsp70 change with the status of the cell (Milarski et al. 1989), which implies a regulatory function rather than a protective one.

Within the DNA repair process, Hsp70s form stable interactions with client proteins. For example, purification of two human enzymes involved in base excision DNA repair (BER), the uracil DNA glycosylase and DNA polymerase $\beta$, identified Hsp70 as an associated protein (Mendez et al. 2003). The interaction with DNA polymerase $\beta$ stimulates the gap-filling activity of the enzyme (Mendez et al. 2003). Furthermore, Hsp70 binds to the HAP1 endonuclease and enhances its catalytic activity (Kenny et al. 2001). Perhaps notably, leukemia cells expressing higher levels of Hsp70 display enhanced BER activity in vivo (Bases 2006). As Hsp70 colocalizes with other components in the nucleus, including PARP1 and XRCC1 
(Kotoglou et al. 2009), Hsp70 may be a general facilitator of the BER pathway.

The Hsp70s were founded by their ability to dislodge the $\lambda \mathrm{P}$ protein from the $\lambda$ origin of DNA replication (Fig. 1) (Georgopoulos 2006). Yet, the capabilities of this class of molecular chaperones seem almost endless because Hsp70s assist polypeptides as they emerge from a ribosome, regulate mature structures, triage damage proteins, and guide degradation of worn factors (Mayer and Bukau 2005). With the exception of nascent chain folding, all of these protein life-cycle steps occur with polypeptides working at or near the DNA no matter whether a nuclear membrane encapsulates the genome or not. Hence, the necessity of an active molecular chaperone system, which includes Hsp70, work- ing along the genome is a natural sector of the proteostasis process.

\section{HSP90 MOLECULAR CHAPERONES}

Heat shock protein 90 (Hsp90) is an essential molecular chaperone ubiquitously expressed and conserved in almost all organisms (Johnson and Brown 2009). In contrast to Hsp70 and Hsp60 families, Hsp90s are not considered facilitators of nascent protein folding, rather these molecular chaperones mediate late steps in protein maturation or maintain metastable proteins in activatable states (Schopf et al. 2017). Based on high-throughput screens meant to identify physical or genetic associations, Hsp90 has an expansive interactome as $\sim 20 \%$ of the yeast

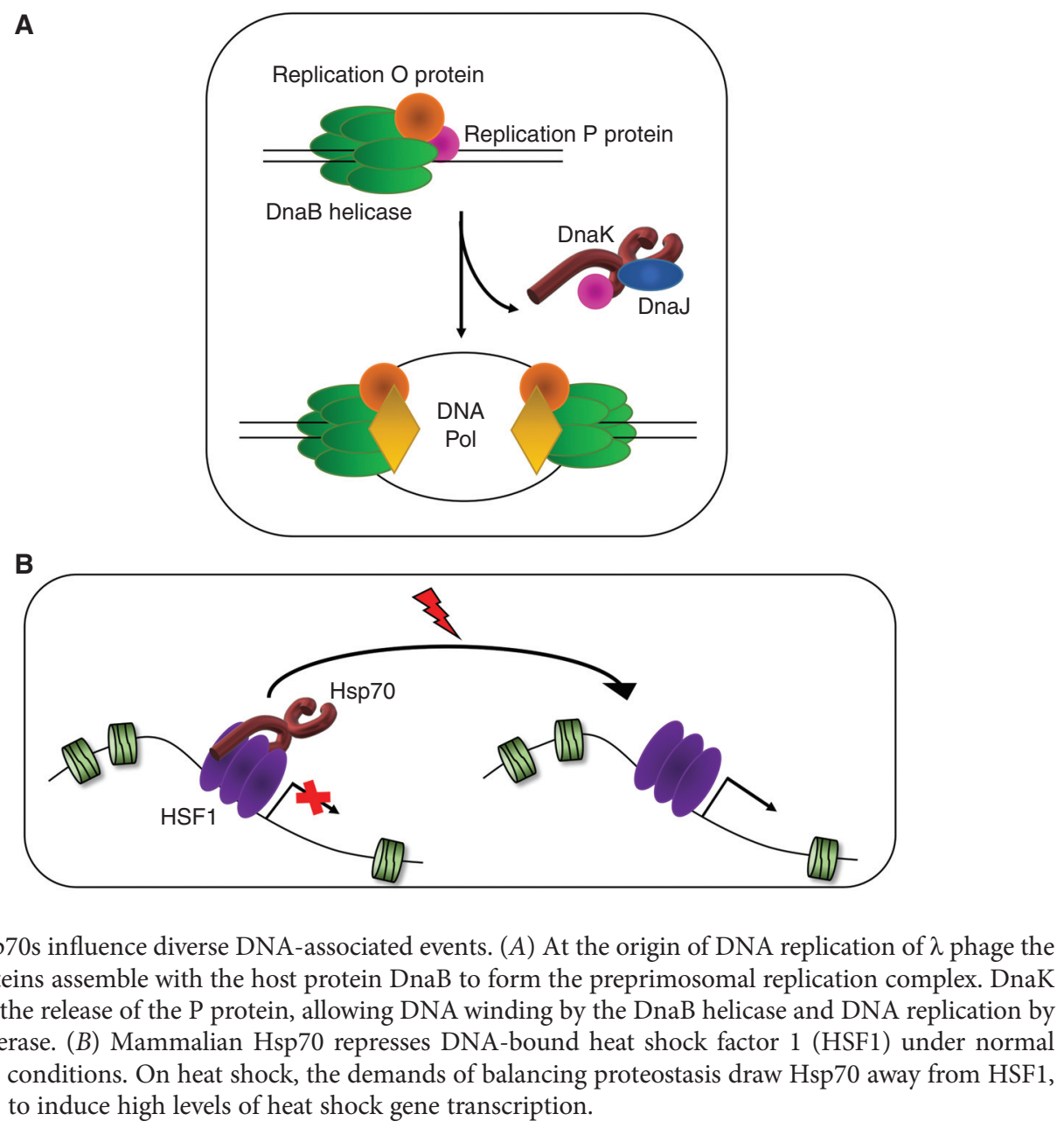

Figure 1. Hsp70s influence diverse DNA-associated events. $(A)$ At the origin of DNA replication of $\lambda$ phage the $\mathrm{O}$ and $\mathrm{P}$ proteins assemble with the host protein DnaB to form the preprimosomal replication complex. DnaK helps trigger the release of the P protein, allowing DNA winding by the DnaB helicase and DNA replication by DNA polymerase. (B) Mammalian Hsp70 represses DNA-bound heat shock factor 1 (HSF1) under normal physiological conditions. On heat shock, the demands of balancing proteostasis draw Hsp70 away from HSF1, freeing HSF1 to induce high levels of heat shock gene transcription. 
Z. Gvozdenov et al.

proteome is connected to it (Millson et al. 2005; Zhao et al. 2005; McClellan et al. 2007). Intriguingly, $20 \%$ of the identified Hsp90 interactors are established nuclear proteins, implying that Hsp90 has an extensive role in the nucleus.

Although Hsp90 was first observed in the early heat shock experiments (Tissiéres et al. 1974; Ashburner and Bonner 1979), functional work on this chaperone began in the steroid hormone receptor signaling field in which Hsp90 was identified as a component of aporeceptor (i.e., hormone-free) complexes (Joab et al. 1984). Hsp90 associated with the 8-9S nontransformed forms of either progesterone receptor (PR) or glucocorticoid receptor (GR) facilitate a high-affinity hormone-binding state (Fig. 2) (Joab et al. 1984; Catelli et al. 1985; Sanchez et al. 1985; Picard et al. 1990; Pratt and Toft 1997). Significantly, these reports helped establish the classic principle that Hsp90 maintains metastable proteins in activatable states.

Perhaps paradoxically, the concept that Hsp90 does not have a nuclear presence/function was first proposed in the steroid field as a means to justify the cytosolic localization of GR in the absence of activating hormone (Sanchez et al. 1985). Yet, evidence that Hsp90 was physically in the nucleus had already been reported (Collier and Schlesinger 1986; Van Bergen en Henegouwen et al. 1987) even in conjunction with another steroid receptor, PR (Gasc et al. 1990). Although indirect, the first demonstration that Hsp90 might have a functional role in the nucleus was the finding that overexpression of HSPs, particularly Hsp90, prevents blockage of RNA splicing at elevated temperatures (Yost and Lindquist 1986). Notably, both heat shock and quiescence growth conditions trigger nuclear enrichment of Hsp90 (Carbajal et al. 1990; Morcillo et al. 1993; Tapia and Morano 2010).

In Drosophila salivary glands, Hsp90 nucleates at select DNA puffs (93D in D. melanogaster, 48B in Drosophila hydei, or at telomeric Balbiani ring puffs in Chironomus thummi) under heat shock conditions (Morcillo et al. 1993). Inhibition of transcription but not protein synthesis blocked Hsp90's localization to these puffs, implying a chaperone role in tran- scription events (Morcillo et al. 1993) - whether Hsp90 impacts either or both RNA production or processing has not been resolved. Of the nine puffs induced by heat shock in Drosophila salivary glands, $93 \mathrm{D}$ or the $h s r \omega$ locus is unique in not coding for a protein product but rather producing several noncoding RNAs that minimally control the organization and migration of hnRNPs (Spradling et al. 1977; Fini et al. 1989; Lakhotia and Mutsuddi 1996; Prasanth et al. 2000). Significantly, mutants of hsr synthetic lethal phenotypes with the Hsp90 allele $h s p 83_{\text {e4a }}$, indicating a critical physiological connection (Lakhotia and Ray 1996).

In normal cells, the noncoding transcripts of hsr $\omega$ form many small omega speckles within the interchromatin space that merge into larger speckles on heat shock, colocalizing with hnRNPs that migrate into the 93D puff as the heat shock continues (Prasanth et al. 2000). Similarly, Hsp90 associates with perichromatin RNP fibrils that relocalize to the 93D puff following heat shock (Carbajal et al. 1990; Morcillo et al. 1993). Unfortunately, the mechanistic contributions of Hsp90 to the 93D puff (e.g., protection of RNP proteins, speckle migration, etc.) are yet to be resolved.

Independent of the 93D puff, a number of studies have shown functional effects of Hsp90 with transcription factors. Although it was well established that Hsp90 maintains steroid receptors in activatable forms (Pratt and Toft 1997), an additional downstream role was unexpected. Yet, super stoichiometric levels of Hsp90 dissociate estrogen receptor (ER) from its cognate DNA (estrogen response element), while lowering the concentration of Hsp90 in the reaction allowed ER to rebind its response element in vitro (Sabbah et al. 1996). Comparably, an increased Hsp90/GR ratio in the nucleus led to a decreased GR-DNA interaction even in the presence of hormone (Kang et al. 1999). Furthermore, release of GR from chromatin was impaired by the Hsp90 inhibitor geldanamycin leading to the proposed role of Hsp90 in chromatin recycling of steroid receptors (Liu and DeFranco, 1999). With the development of the chromatin immunoprecipitation (ChIP) assay, Hsp90 along with its cochaperone p23 were 


\section{A}

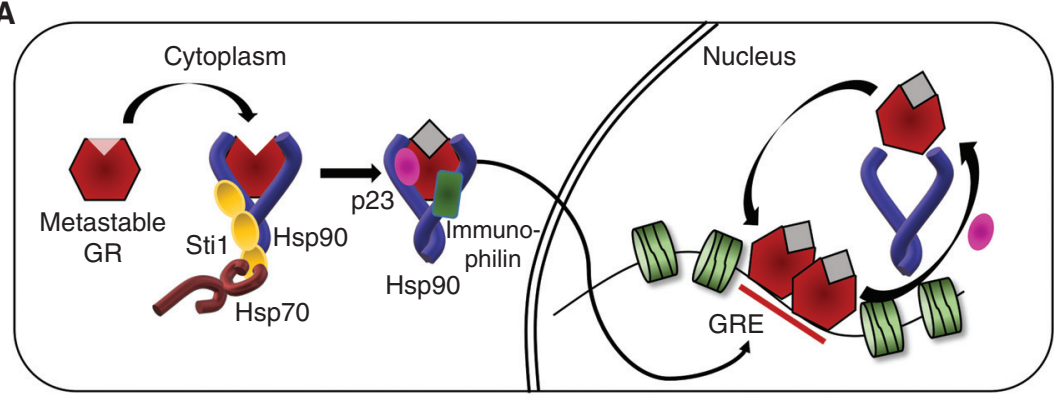

B

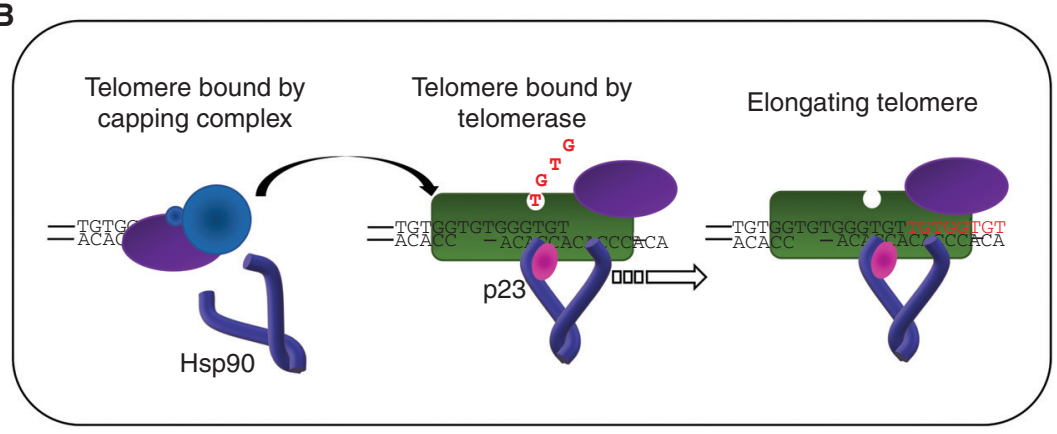

C



Figure 2. Hsp90s mediate the assembly and disassembly of diverse nuclear macromolecular structures. $(A)$ In the cytoplasm, Hsp90 maintains the metastable glucocorticoid receptor (GR) in a high-affinity ligand-binding form. Following hormone binding, GR translocates to the nucleus where Hsp90 now serves to mediate a dynamic DNA-binding interaction between GR and glucocorticoid response elements (GREs). (B) Hsp90 facilitates the switch between telomere capping and telomerase-dependent elongating complexes. Furthermore, Hsp90 supports the DNA binding and nucleotide addition activities of telomerase during the extension phase. (C) Hsp90 triggers the release of a nucleosome-bound RSC chromatin remodeling complex, thereby facilitating its dispersal across the chromatin landscape. (Figure continues on following page.)

shown to directly associate at GR-controlled DNA response elements in vivo, thereby triggering release of the receptor and modulating the transcriptional activation potential of GR and other transcription factors (Freeman et al. 2000; Freeman and Yamamoto 2002). Together, these reports established the Hsp90 chaperone system as an important machine for maintaining a dynamic receptor-DNA interaction that allows re- ceptors to recruit the numerous needed coactivators for transcription as well as the capacity to monitor the cellular concentrations of activating ligand (Freeman and Yamamoto 2001; DeZwaan and Freeman 2008; Hager et al. 2009).

Within the transcription process, Hsp90 shares numerous additional links beyond transcription factors with chromatin modifiers being a highlight (Echtenkamp and Freeman 
Z. Gvozdenov et al.

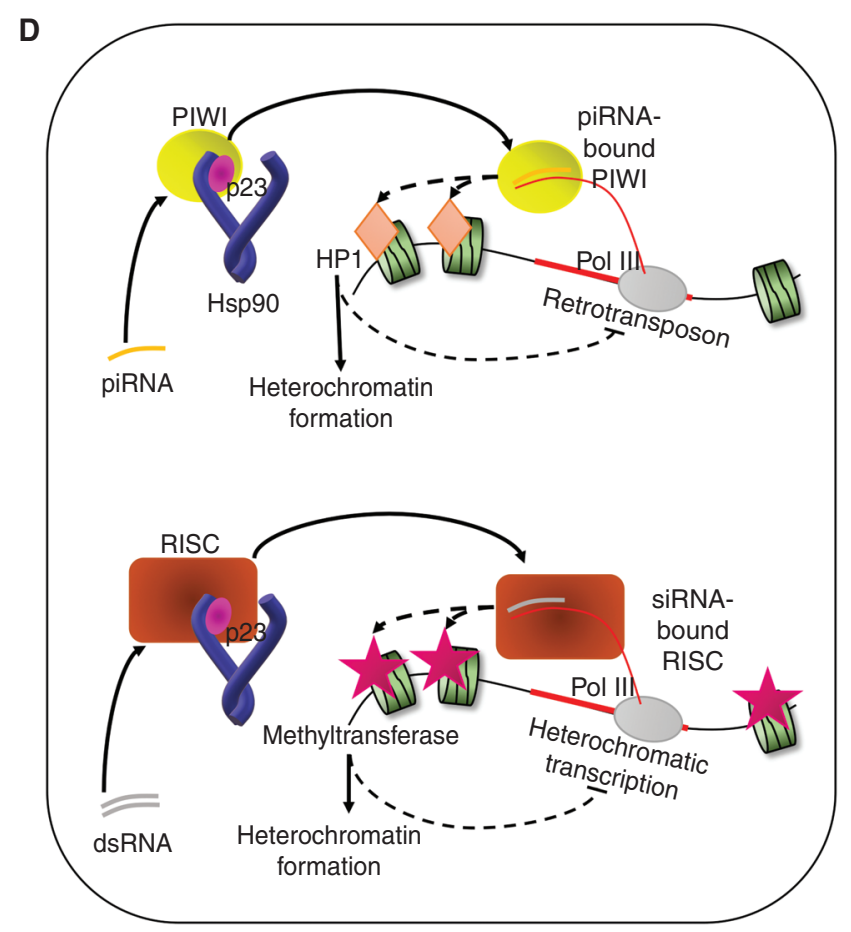

Figure 2. (Continued) (D) Hsp90 assists the loading of piRNAs into PIWI proteins as well as short interfering RNAs (siRNAs) into RNA-induced silencing complexes (RISCs) that direct retrotransposon silencing and heterochromatin formation. dsRNA, Double-stranded RNA.

2014). For instance, in colorectal carcinoma cells the SMYD3 histone methyltransferase requires Hsp90 for activity (Hamamoto et al. 2004). Furthermore, inhibition of Hsp90 leads to depletion of the central developmental regulator trithorax that in turn reduces the level of active chromatin at numerous gene loci including the Hox genes (Tariq et al. 2009). Similarly, compromised Hsp90 function delays nucleosome removal from the GAL1 promoter in yeast thereby impairing transcriptional activation (Floer et al. 2008). In D. melanogaster, Hsp90 was found at most gene promoters being primarily localized to the upstream nucleosome-depleted regions (NDRs) (Sawarkar et al. 2012). Mapping of budding yeast NDRs showed a reliance of open chromatin regions on both Hsp90 and its cochaperone p23 (Echtenkamp et al. 2016). At the least, Hsp90 supports NDRs by mobilizing the RSC chromatin remodeler between target sites, whereas p23 facilitates the nucleosome remodeling action of RSC. Notably, Hsp90 has been genetically and/or physically linked to most chromatin modifiers and therefore its roles with packaged genomes are expected to expand considerably with future studies.

In addition to chromatin packaging events, Hsp90 is known to influence the dynamics of protein-DNA interactions at the ends of eukaryotic chromosomes (telomeres). Here, Hsp90 serves multiple roles. During most of the cell cycle, the termini of eukaryotic chromosomes are capped by a variety of proteins that protect the DNA ends from damage (Wellinger and Zakian 2012). In budding yeast, the primary capping complex, Cdc13-Stn1-Ten1 (CST), is dislodged by Hsp90 to allow access by the telomerase enzyme, which extends the DNA and maintains genomic integrity (DeZwaan et al. 2009). Besides clearing CST, Hsp90 fosters the DNA binding and nucleotide addition activities of telomerase, which is a specialized reverse transcriptase, and mutations in Hsp90 correlate with shorten telomeric DNA (Toogun et al. 
2008). Significantly, human Hsp90 fosters the assembly of the telomerase protein subunit with its RNA template and remains associated with the active enzyme in a manner comparable to yeast (Holt et al. 1999; Forsythe et al. 2001).

Besides the specialized reverse transcriptase of normal eukaryotic cells, Hsp90 also supports the viral reverse transcriptase of hepatitis $B$ in which Hsp90 and p23 are actually packaged with the viral particles to ensure proper priming of DNA synthesis following infection (Hu and Seeger 1996; Hu et al. 1997). Intriguingly, Hsp90 appears to serve a diversity of RNA-binding proteins including in the assembly of piRNAs with PIWI proteins and loading of RNA into the RISCs (Iwasaki et al. 2010, 2015; Miyoshi et al. 2010; Izumi et al. 2013). Notably, RNAidependent heterochromatin assembly is reliant on Hsp90 including for the repression of retrotransposons (Ichiyanagi et al. 2014; Okazaki et al. 2018).

Hsp90 may also have a role in the DNA repair process. Hsp90 is phosphorylated in response to DNA damage by ataxia-telangiectasia-mutated (ATM) (Elaimy et al. 2016) and accumulates in the DNA double strand break foci, while compromised Hsp90 activity leads to defective repair (Quanz et al. 2012). Addition of an Hsp90 inhibitor in combination with radiation results in increased killing of tumorigenic cell lines (Russell et al. 2003; Bull et al. 2004). Although phosphorylation of $\mathrm{Hsp} 90$ is required for the formation of Hsp90-HCLK2-MRN2 complex for successful ATM/ATR signaling and homologous recombination repair (Cheng et al. 2017), higher levels of Hsp90 itself lead to genomic instability on DNA damage through suppression of the transcription of RAD53 (Khurana et al. 2016) demonstrating a complex Hsp90-dependent regulation of the DNA repair pathway. In yeast, several potential Hsp90 interactors in the DNA repair process have been identified (Zhao et al. 2005; McClellan et al. 2007). One such interactor is Ssl2, a DNA helicase that is a part of the RNA polymerase holoenzyme and an important incision factor for nucleotide excision repair. Mutations in SSL2, when combined with HSP82 and HSC82 mutant alleles lead to synthetic growth defects (Flom et al. 2005). Hsp90 could stabilize several DNA repair proteins as exemplified by Rad51, ATM, NBN, and XRCC1 (Fang et al. 2014; Suhane et al. 2015; Pennisi et al. 2017), and/or could regulate the dynamics of the DNA repair process. However, the complete mechanism behind Hsp90 action during DNA repair has not yet been elucidated.

Despite the early prognosis that Hsp90 retains client proteins outside of the nuclear compartment (Sanchez et al. 1985), it is now evident that Hsp90 has both a physical and functional nuclear presence. As the budding yeast Hsp90 interactome contains hundreds of nuclear factors, it will be interesting to learn the full range of action of Hsp90 in the nucleus. Although few studies have reported a role for the bacterial Hsp90 homolog HtpG with DNA-associated proteins, an interaction with the DNA replication protein DnaA has been shown (Grudniak et al. 2015). Perhaps it would be worthwhile investigating the influence of HtpG with DNA pathways (for a more complete review of Hsp90, see Biebl and Buchner 2019).

\section{HSP60/CCT CHAPERONINS}

Early work on GroEL and its plant homolog RuBisCO (ribulose-1,5-bisphosphate carboxylase/oxygenase)-binding protein were instrumental in establishing molecular chaperones as facilitators of protein folding and macromolecular complex assembly. Besides supporting $\lambda$ phage head assembly, initial work showed that GroEL was required for tail assembly of T5 phages (Zweig and Cummings 1973) and the first identified eukaryotic GroEL homolog was shown to mediate folding and assembly of the RuBisCO enzyme (Barraclough and Ellis 1980; Hemmingsen et al. 1988; Goloubinoff et al. 1989). Hence, GroEL and the RuBisCO-binding protein represent the founding members of the chaperonins (Hemmingsen et al. 1988), which also includes mitochondrial Hsp60 and the tailless complex polypeptide (TCP1) ring complex (TRiC) or chaperonin containing TCP1 (CCT) (Fig. 3).

In addition to phage proteins, several studies have shown that GroEL and its cochaperone 


\section{Z. Gvozdenov et al.}

A

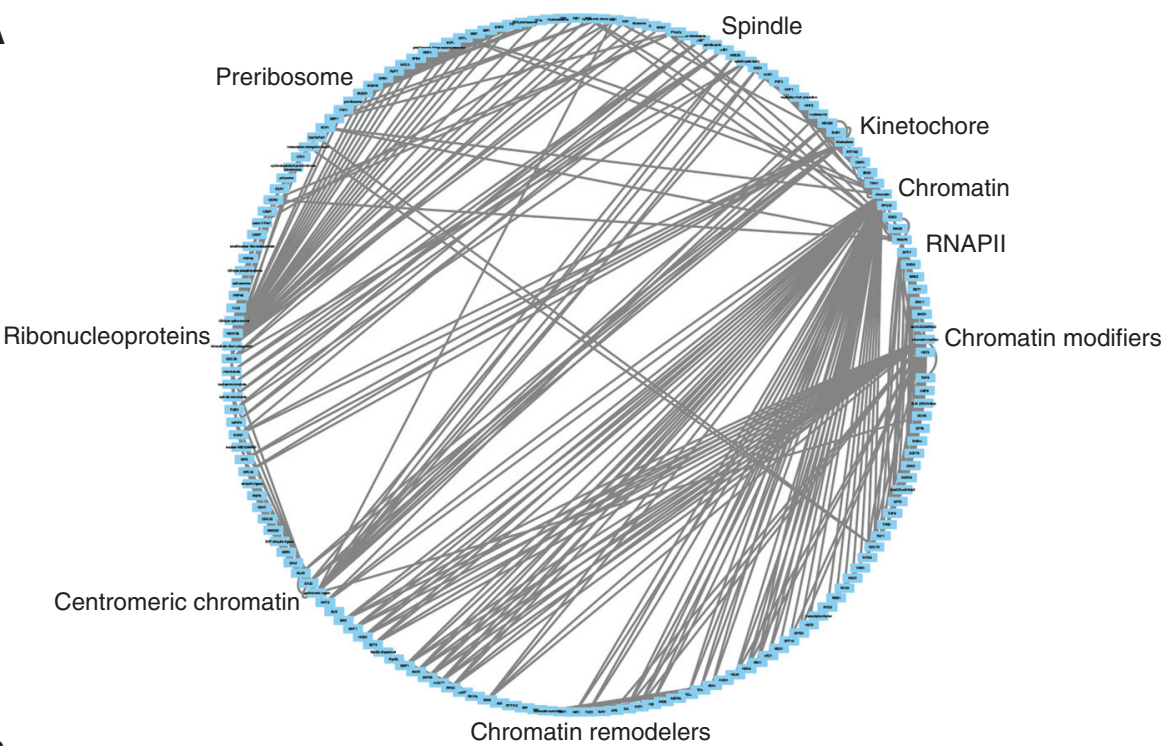

B
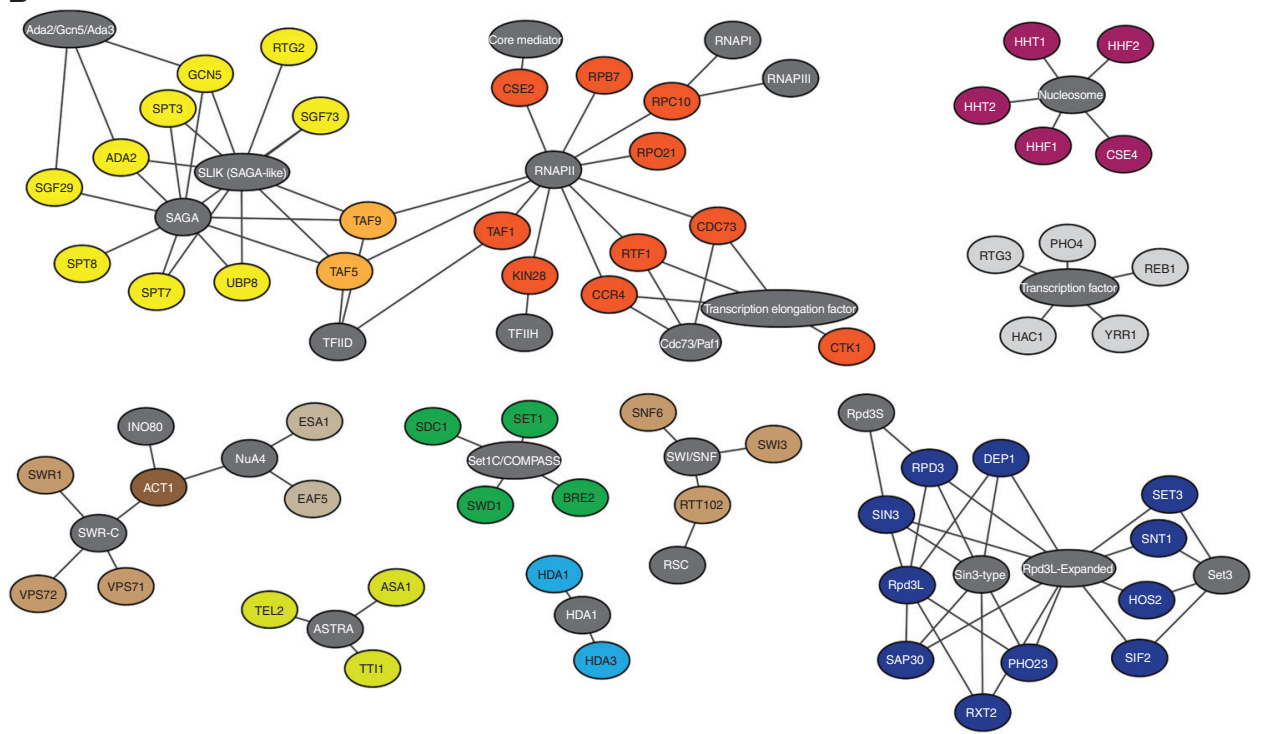

Figure 3. Hsp60s are linked to a variety of known nuclear proteins/protein complexes. (A) Physical and genetic chaperonin containing TCP1 (CCT)-interactors from the Saccharomyces Genome Database (SGD) were assigned to macromolecular complexes with GO slim and plotted using cytoscape. (B) The nuclear CCT-interacting hits are enriched in multisubunit protein complexes including structures involved in chromatin modification, chromatin remodeling, and RNA polymerase complex.

GroES support proteins and protein complexes working along the DNA. For instance, normal RNA polymerase copurifies with GroEL (Ishihama et al. 1976). In the absence of the nonessential RNA polymerase subunit $\omega$ purified RNA polymerase loses activity on removal of GroEL; however, polymerase function can be regained if the enzyme is renatured in the presence of $\omega$ (Mukherjee et al. 1999). Whether this represents the folding activity of GroEL (Ziemienowicz et al. 1993) or whether GroEL is actively contributing to RNA polymerase activity in vivo has 
not been shown. Use of a temperature-sensitive groES strain revealed that bacterial DNA and RNA synthesis were defective at the nonpermissive temperature suggesting these pathways are continuously dependent on the GroEL/ES complex (Wada and Itikawa 1984). At the very least, GroEL fosters the activity of the seemingly mature DNA polymerase V enzyme during DNA lesion bypass (Petit et al. 1994). However, as bacteria do not have nuclear compartments, distinguishing whether GroEL serves only in the biogenesis of RNA/DNA polymerases or whether the chaperonin remains associated with the active complexes is difficult relative to eukaryotes in which active polymerases are compartmentalized in the nucleus.

CCT, on the other hand, is expressed in mammalian cells in which nascent protein folding events and DNA are physically separated by a nuclear membrane. Although the first report on the cellular localization of CCT implied that the chaperonin was strictly cytosolic (Lewis et al. 1992), an examination of the presented data suggests CCT has a low nuclear occupancy. Subsequent investigations showed that TRiC-P5 is found in the nuclear matrix of human B lymphocytes and leukocytes (Joly et al. 1994; Gerner et al. 1999), as well as CCT subunits $\alpha$ and $\gamma$ in mouse P19 embryonal carcinoma cells (Roobol and Carden 1999). Moreover, TCP1 isoforms accumulate in the nuclear matrix during apoptotic chromatin condensation in HeLa cells (Gerner et al. 2002) and CCT associated with both constitutive and facultative heterochromatin during murine spermatogenesis (Souès et al. 2003). Despite these observations, the mechanistic implications for nuclear TCP1/CCT are still unclear.

A physical connection between a eukaryotic chaperonin and a nuclear protein client has been reported. Mass spectrometry analysis of affinity purified histone deacetylases Set3 complex (Set3C) or Rpd3 complexes (Rpd3S and Rpd3L) showed an association with seven or eight, respectively, CCT subunits (Shevchenko et al. 2002; Carrozza et al. 2005). Yet, it was unclear whether the interactions were limited to the cytosol for classical chaperone posttranslational events, or whether it was in the nucleus to meet more specialized requirements. Minimally, CCT folds and assimilates the deacetylase subunit HDAC3 into the Set3C structure (Guenther et al. 2002). Whether CCT is used to assemble Set3C in the nucleus or just within the cytoplasm has not been determined. As most nuclear pathways rely on numerous large protein complexes, which are often modular in nature (i.e., different modules are incorporated depending on the precise genomic need/location), to function it is plausible that chaperonins are exploited to rapidly assemble the different macromolecular variants as needed.

Perhaps notably, high-throughput studies have connected CCT to a variety of nuclear proteins, including transcriptional components such as TAF5, a subunit of TFIID general transcription factor, members of CCR4-NOT transcriptional complex, and the SAGA histone acetyltransferase complex (Ho et al. 2002). In addition, CCT physical and genetic interaction networks encompass other chromatin regulators such as the SWR1 and SWI/SNF chromatin remodelers, Set1 methyltransferase complex (Set1C), and type II histone deacetylase complex (HDAC) (Dekker et al. 2008; Shevchenko et al. 2008). Overall, the Saccharomyces cerevisiae yeast database currently shows 377 physical and genetic CCT interactors with $48 \%$ being nuclear proteins. Yet, the influence of CCT within nuclear pathways remains largely unexplored.

\section{SUMMARY}

Proteostasis is a highly complex process as it oversees the biogenesis, maintenance, and disposal of all cellular polypeptides. Here, we have focused on one sector of proteostasis - the roles of the main molecular chaperones (i.e., Hsp70, Hsp90, and Hsp60) in the maintenance of a healthy proteome working along a genome. As such, there is still much to consider. For example, in eukaryotes, proteasome particles are either evenly distributed between the cytoplasm and nucleoplasm (mammals) or are primarily enriched at the inner nuclear envelope (yeast) (Wilkinson et al. 1998; Brooks et al. 2000). Intriguingly, Hsp70 and its Hsp40 cochaperone have been shown to mediate the nuclear import 
Z. Gvozdenov et al.

of misfolded proteins for degradation in the nucleus (Park et al. 2013; Prasad et al. 2018). Thus, the nuclear space must also manage significant protein quality control events leading to protein degradation (Gallagher et al. 2014; Nielsen et al. 2014). However, before reaching the final phase of a protein's life cycle (i.e., degradation), molecular chaperones provide significant support, as described above. Because the maintenance of a system is more efficient than de novo synthesis and destruction, the capacity of molecular chaperones to perpetuate an active native protein landscape provides a significant benefit to the health of a cell. In the case of DNA- and/or nuclear-associated pathways, the Hsp70, Hsp90, and Hsp60 chaperones provide an effective means to keep the various polypeptides in folded functional states (classic chaperone action), as well as maintaining the multitude of required macromolecular structures in a dynamic state fostering rapid assembly/disassembly of the modular complexes and promoting redundant interactions with the high-affinity DNA ligand.

\section{REFERENCES}

${ }^{*}$ Reference is also in this collection.

Abravaya K, Myers MP, Murphy SP, Morimoto RI. 1992. The human heat shock protein hsp70 interacts with HSF, the transcription factor that regulates heat shock gene expression. Genes Dev 6: 1153-1164. doi:10.1101/ gad.6.7.1153

Arrigo AP, Fakan S, Tissières A. 1980. Localization of the heat shock-induced proteins in Drosophila melanogaster tissue culture cells. Dev Biol 78: 86-103. doi:10.1016/ 0012-1606(80)90320-6

Arsène F, Tomoyasu T, Bukau B. 2000. The heat shock response of Escherichia coli. Int J Food Microbiol 55: 3-9. doi:10.1016/S0168-1605(00)00206-3

Ashburner M, Bonner JJ. 1979. The induction of gene activity in Drosophila by heat shock. Cell 17: 241-254. doi:10.1016/0092-8674(79)90150-8

Balch WE, Morimoto RI, Dillin A, Kelly JW. 2008. Adapting proteostasis for disease intervention. Science 319: 916919. doi:10.1126/science.1141448

Barraclough R, Ellis RJ. 1980. Protein synthesis in chloroplasts IX: Assembly of newly-synthesized large subunits into ribulose bisphosphate carboxylase in isolated intact pea chloroplasts. BBA Sect Nucleic Acids Protein Synth 608: $19-31$.

Bases R. 2006. Heat shock protein 70 enhanced deoxyribonucleic acid base excision repair in human leukemic cells after ionizing radiation. Cell Stress Chaperones 11: 240249. doi:10.1379/CSC-185R.1

* Biebl MM, Buchner J. 2019. Structure, function, and regulation of the Hsp90 machinery. Cold Spring Harb Perspect Biol doi:10.1101/cshperspect.a034017

Brooks P, Fuertes G, Murray RZ, Bose S, Knecht E, Rechsteiner MC, Hendil KB, Tanaka K, Dyson J, Rivett J. 2000. Subcellular localization of proteasomes and their regulatory complexes in mammalian cells. Biochem J346: 155-161. doi:10.1042/bj3460155

Bukau B, Walker GC. 1989. Cellular defects caused by deletion of the Escherichia coli dnaK gene indicate roles for heat shock protein in normal metabolism. J Bacteriol 171: 2337-2346. doi:10.1093/emboj/17.22.6465

Bull EEA, Dote H, Brady KJ, Burgan WE, Carter DJ, Cerra MA, Oswald KA, Hollingshead MG, Camphausen K, Tofilon PJ. 2004. Enhanced tumor cell radiosensitivity and abrogation of G2 and S phase arrest by the Hsp90 inhibitor 17-(dimethylaminoethylamino)-17-demethoxygeldanamycin. Clin Cancer Res 10: 8077-8084. doi:10. 1158/1078-0432.CCR-04-1212

Carbajal ME, Valet JP, Charest PM, Tanguay RM. 1990. Purification of Drosophila hsp83 and immunoelectron microscopic localization. Eur J Cell Biol 52: 147-156.

Carrozza MJ, Li B, Florens L, Suganuma T, Swanson SK, Lee KK, Shia WJ, Anderson S, Yates J, Washburn MP, et al. 2005. Histone H3 methylation by Set 2 directs deacetylation of coding regions by $\mathrm{Rpd} 3 \mathrm{~S}$ to suppress spurious intragenic transcription. Cell 123: 581-592. doi:10.1016/ j.cell.2005.10.023

Catelli MG, Binart N, Jung-Testas I, Renoir JM, Baulieu EE, Feramisco JR, Welch WJ. 1985. The common 90-kd protein component of non-transformed " $8 \mathrm{~S}$ " steroid receptors is a heat-shock protein. EMBO J 4: 3131-3135. doi:10.1002/j.1460-2075.1985.tb04055.x

Cheng AN, Fan CC, Lo YK, Kuo CL, Wang HC, Lien IH, Lin SY, Chen CH, Jiang SS, Chang IS, et al. 2017. Cdc7-Dbf4mediated phosphorylation of HSP90-S164 stabilizes HSP90-HCLK2-MRN complex to enhance ATR/ATM signaling that overcomes replication stress in cancer. Sci Rep 7: 17024. doi:10.1038/s41598-017-17126-2

Collier NC, Schlesinger MJ. 1986. The dynamic state of heat shock proteins in chicken embryo fibroblasts. J Cell Biol 103: 1495-1507. doi:10.1083/jcb.103.4.1495

Dekker C, Stirling PC, McCormack EA, Filmore H, Paul A, Brost RL, Costanzo M, Boone C, Leroux MR, Willison KR. 2008. The interaction network of the chaperonin CCT. EMBO J 27: 1827-1839. doi:10.1038/emboj.2008. 108

DeZwaan DC, Freeman BC. 2008. Hsp90: The Rosetta Stone for cellular protein dynamics? Cell Cycle 7: 1006-1012. doi:10.4161/cc.7.8.5723

DeZwaan DC, Toogun OA, Echtenkamp FJ, Freeman BC. 2009. The Hsp 82 molecular chaperone promotes a switch between unextendable and extendable telomere states. Nat Struct Mol Biol 16: 711-716. doi:10.1038/nsmb.1616

* Dobson CM, Knowles TPJ, Vendruscolo M. 2019. The Amyloid phenomenon and its significance in biology and medicine. Cold Spring Harb Perspect Biol doi:10.1101/ cshperspect.a033878 
Echtenkamp FJ, Freeman BC. 2014. Molecular chaperonemediated nuclear protein dynamics. Curr Prot Pept Sci 15: 216-224. doi:10.2174/1389203715666140331112230

Echtenkamp FJ, Gvozdenov Y, Adkins NL, Zhang Y, LynchDay MA, Watanabe S, Peterson CL, Freeman BC. 2016 Hsp90 and p23 molecular chaperones control chromatin architecture by maintaining the functional pool of the RSC chromatin remodeler. Mol Cell 64: 888-899. doi: 10.1016/j.molcel.2016.09.040

Elaimy AL, Ahsan A, Marsh K, Pratt WB, Ray D, Lawrence TS, Nyati MK. 2016. ATM is the primary kinase responsible for phosphorylation of Hsp90 $\alpha$ after ionizing radiation. Oncotarget 7: 82450-82457. doi:10.18632/ oncotarget.12557

Fang Q, Inanc B, Schamus S, Wang XH, Wei L, Brown AR, Svilar D, Sugrue KF, Goellner EM, Zeng X, et al. 2014 HSP90 regulates DNA repair via the interaction between XRCC1 and DNA polymerase $\beta$. Nat Commun 5: 5513 5539. doi:10.1038/ncomms6513

Fini ME, Bendena WG, Pardue ML. 1989. Unusual behavior of the cytoplasmic transcript of hsrw: An abundant, stress-inducible RNA that is translated but yields no detectable protein product. J Cell Biol 108: 2045-2057. doi:10.1083/jcb.108.6.2045

Floer M, Bryant GO, Ptashne M. 2008. HSP90/70 chaperones are required for rapid nucleosome removal upon induction of the GAL genes of yeast. Proc Natl Acad Sci 105: 2975-2980. doi:10.1073/pnas.0800053105

Flom G, Weekes J, Johnson JL. 2005. Novel interaction of the Hsp90 chaperone machine with Ssl2, an essential DNA helicase in Saccharomyces cerevisiae. Curr Genet 47: 368 380. doi:10.1007/s00294-005-0580-6

Forsythe HL, Jarvis JL, Turner JW, Elmore LW, Holt SE. 2001. Stable association of hsp90 and p23, but not hsp70, with active human telomerase. J Biol Chem 276: 15571-15574. doi:10.1074/jbc.C100055200

Freeman BC, Yamamoto KR. 2001. Continuous recycling: A mechanism for modulatory signal transduction. Trends Biochem Sci 26: 285-290. doi:10.1016/S0968-0004(01) 01834-5

Freeman BC, Yamamoto KR. 2002. Disassembly of transcriptional regulatory complexes by molecular chaperones. Science 296: 2232-2235. doi:10.1126/science. 1073051

Freeman BC, Felts SJ, Toft DO, Yamamoto KR. 2000. The p23 molecular chaperones act at a late step in intracellular receptor action to differentially affect ligand efficacies. Genes Dev 14: 422-434.

Gallagher PS, Oeser ML, Abraham AC, Kaganovich D, Gardner RG. 2014. Cellular maintenance of nuclear protein homeostasis. Cell Mol Life Sci 71: 1865-1879. doi:10.1007/s00018-013-1530-y

Gasc JM, Renoir JM, Faber LE, Delahaye F, Baulieu EE. 1990 Nuclear localization of two steroid receptor-associated proteins, hsp90 and p59. Exp Cell Res 186: 362-367. doi:10.1016/0014-4827(90)90317-4

Georgopoulos C. 2006. Toothpicks, serendipity and the emergence of the Escherichia coli DnaK (Hsp70) and GroEL (Hsp60) chaperone machines. Genetics 174: 1699-1707. doi:10.1534/genetics.104.68262

Georgopoulos CP, Hendrix RW, Casjens SR, Kaiser AD. 1973. Host participation in bacteriophage $\lambda$ head assem- bly. J Mol Biol 76: 45-60. doi:10.1016/0022-2836(73) 90080-6

Gerner C, Holzmann K, Meissner M, Gotzmann J, Grimm R, Sauermann G. 1999. Reassembling proteins and chaperones in human nuclear matrix protein fractions. $J$ Cell Biochem 74: 145-151. doi:10.1002/(SICI)1097-4644 (19990801)74:2<145::AID-JCB1>3.0.CO;2-\#

Gerner C, Gotzmann J, Fröhwein U, Schamberger C, Ellinger A, Sauermann G. 2002. Proteome analysis of nuclear matrix proteins during apoptotic chromatin condensation. Cell Death Differ 9: 671-681. doi:10.1038/sj.cdd. 4401010

Goldfless SJ, Morag AS, Belisle KA, Sutera VA, Lovett ST. 2006. DNA repeat rearrangements mediated by DnaKdependent replication fork repair. Mol Cell 21: 595-604. doi:10.1016/j.molcel.2006.01.025

Goloubinoff P, Christeller JT, Gatenby AA, Lorimer GH. 1989. Reconstitution of active dimeric ribulose bisphosphate carboxylase from an unfolded state depends on two chaperonin proteins and Mg-ATP. Nature 342: 884-889. doi:10.1038/342884a0

Grudniak AM, Markowska K, Wolska KI. 2015. Interactions of Escherichia coli molecular chaperone HtpG with DnaA replication initiator DNA. Cell Stress Chaperones 20: 951957.

Guenther MG, Yu J, Kao GD, Yen TJ, Lazar MA. 2002. Assembly of the SMRT-histone deacetylase 3 repression complex requires the TCP-1 ring complex. Genes Dev 16: 3130-3135. doi:10.1101/gad.1037502

Hackam AS, Singaraja R, Zhang T, Gan L, Hayden MR. 1999. In vitro evidence for both the nucleus and cytoplasm as subcellular sites of pathogenesis in Huntington's disease. Hum Mol Genet 8: 25-33. doi:10.1093/hmg/8.1.25

Hager GL, McNally JG, Misteli T. 2009. Transcription dynamics. Mol Cell 35: 741-753. doi:10.1016/j.molcel. 2009.09.005

Hamamoto R, Furukawa Y, Morita M, Iimura Y, Silva FP, Li M, Yagyu R, Nakamura Y. 2004. SMYD3 encodes a histone methyltransferase involved in the proliferation of cancer cells. Nat Cell Biol 6: 731-740. doi:10.1038/ ncb1151

Hemmingsen SM, Woolford C, van der Vies SM, Tilly K, Dennis DT, Georgopoulos CP, Hendrix RW, Ellis RJ. 1988. Homologous plant and bacterial proteins chaperone oligomeric protein assembly. Nature 333: $330-334$ doi:10.1038/333330a0

Ho Y, Gruhler A, Heilbut A, Bader GD, Moore L, Adams SL, Millar A, Taylor P, Bennett K, Boutilier K, et al. 2002. Systematic identification of protein complexes in Saccharomyces cerevisiae by mass spectrometry. Nature 415: 180-183. doi:10.1038/415180a

Hoffmann HJ, Lyman SK, Lu C, Petit MA, Echols H. 1992. Activity of the Hsp70 chaperone complex-DnaK, DnaJ, and GrpE-in initiating phage $\lambda$ DNA replication by sequestering and releasing $\lambda$ P protein. Proc Natl Acad Sci 89: 12108-12111. doi:10.1073/pnas.89.24.12108

Holt SE, Aisner DL, Baur J, Tesmer VM, Dy M, Ouellette M, Trager JB, Morin GB, Toft DO, Shay JW, et al. 1999. Functional requirement of p23 and Hsp90 in telomerase complexes. Genes Dev 13: 817-826. doi:10.1101/gad. 13.7.817 


\section{Z. Gvozdenov et al.}

Hu J, Anselmo D. 2000. In vitro reconstitution of a functional duck hepatitis B virus reverse transcriptase: Posttranslational activation by Hsp90. J Virol 74: 11447-11455 doi:10.1128/JVI.74.24.11447-11455.2000

Hu J, Seeger C. 1996. Hsp90 is required for the activity of a hepatitis B virus reverse transcriptase. Proc Natl Acad Sci 93: $1060-1064$. doi:10.1073/pnas.93.3.1060

Hu J, Toft DO, Seeger C. 1997. Hepadnavirus assembly and reverse transcription require a multi-component chaperone complex which is incorporated into nucleocapsids. EMBO J 16: 59-68. doi:10.1093/emboj/16.1.59

Hwang DS, Crooke E, Kornberg A. 1990. Aggregated DnaA protein is dissociated and activated for DNA replication by phospholipase or DnaK protein. J Biol Chem 265: 19244-19248.

Ichiyanagi T, Ichiyanagi K, Ogawa A, Kuramochi-Miyagawa S, Nakano T, Chuma S, Sasaki H, Udono H. 2014. HSP90 $\alpha$ plays an important role in piRNA biogenesis and retrotransposon repression in mouse. Nucleic Acids Res 42: 11903-11. doi:10.1093/nar/gku881

Ishihama A, Ikeuchi T, Yura T. 1976. A novel adenosine triphosphatase isolated from RNA polymerase preparations of Escherichia coli. I: Copurification and separation. $J$ Biochem 79: 917-925. doi:10.1093/oxfordjournals. jbchem.a131159

Itikawa H, Ryu J-I. 1979. Isolation and characterization of a temperature-sensitive dnaK mutant of Escherichia coli B J Bacteriol 138: 339-344.

Iwasaki S, Kobayashi M, Yoda M, Sakaguchi Y, Katsuma S, Suzuki T, Tomari Y. 2010. Hsc70/Hsp90 chaperone machinery mediates ATP-dependent RISC loading of small RNA duplexes. Mol Cell 39: 292-299. doi:10.1016/j. molcel.2010.05.015

Iwasaki S, Sasaki HM, Sakaguchi Y, Suzuki T, Tadakuma H, Tomari Y. 2015. Defining fundamental steps in the assembly of the Drosophila RNAi enzyme complex. Nature 521: 533-536. doi:10.1038/nature14254

Izumi N, Kawaoka S, Yasuhara S, Suzuki Y, Sugano S, Katsuma S, Tomari Y. 2013. Hsp90 facilitates accurate loading of precursor piRNAs into PIWI proteins. RNA 19: 896-901

* Jayaraj GG, Hipp MS, Hartl FU. 2019. Functional modules of the proteostasis network. Cold Spring Harb Perspect Biol doi:10.1101/cshperspect.a033951

Joab I, Radanyi C, Renoir M, Buchou T, Catelli M-G, Binart N, Mester J, Baulieu EE. 1984. Common non-hormone binding component in non-transformed chick oviduct receptors of four steroid hormones. Nature 308: 850853. doi:10.1038/308850a0

Johnson JL, Brown C. 2009. Plasticity of the Hsp90 chaperone machine in divergent eukaryotic organisms. Cel Stress Chaperones 14: 83-94. doi:10.1007/s12192-0080058-9

Joly EC, Tremblay E, Tanguay RM, Wu Y, Bibor-Hardy V. 1994. TRiC-P5, a novel TCP1-related protein, is localized in the cytoplasm and in the nuclear matrix. J Cell Sci 107: 2851-2859.

Kang KI, Meng X, Devin-Leclerc J, Bouhouche I, Chadli A, Cadepond F, Baulieu EE, Catelli MG. 1999. The molecular chaperone Hsp90 can negatively regulate the activity of a glucocorticosteroid-dependent promoter. Proc Natl Acad Sci 96: 1439-1444. doi:10.1073/pnas.96.4.1439
Kenny MK, Mendez F, Sandigursky M, Kureekattil RP, Goldman JD, Franklin WA, Bases R. 2001. Heat shock protein 70 binds to human apurinic/apyrimidinic endonuclease and stimulates endonuclease activity at abasic sites. J Biol Chem 276: 9532-9536. doi:10.1074/jbc. M009297200

Khurana N, Laskar S, Bhattacharyya MK, Bhattacharyya S. 2016. Hsp90 induces increased genomic instability toward DNA-damaging agents by tuning down RAD53 transcription. Mol Biol Cell 27: 2463-2478. doi:10.1091/ mbc.e15-12-0867

Kim YE, Hipp MS, Bracher A, Hayer-Hartl M, Hartl FU. 2013. Molecular chaperone functions in protein folding and proteostasis. Annu Rev Biochem 82: 323-355. doi:10.1146/annurev-biochem-060208-092442

Kloetzel PM, Bautz EKF. 1983. Heat-shock proteins are associated with hnRNA in Drosophila melanogaster tissue culture cells. $E M B O J$ 2: 705-710. doi:10.1002/j.14602075.1983.tb01488.x

Kotoglou P, Kalaitzakis A, Vezyraki P, Tzavaras T, Michalis LK, Dantzer F, Jung JU, Angelidis C. 2009. Hsp70 translocates to the nuclei and nucleoli, binds to XRCC1 and PARP-1, and protects HeLa cells from single-strand DNA breaks. Cell Stress Chaperones 14: 391-406. doi:10.1007/ s12192-008-0093-6

Lakhotia SC, Mutsuddi M. 1996. Heat shock but not benzamide and colchicine response elements are present within the $-844 \mathrm{bp}$ upstream region of the hrs $\omega$ gene of Drosophila melanogaster. J Biosci 21: 235-246. doi:10.1007/ BF02703111

Lakhotia SC, Ray P. 1996. Hsp83 mutation is a dominant enhancer of lethality associated with absence of the nonprotein coding $h s r \omega$ locus in Drosophila melanogaster. J Biosci 21: 207-219. doi:10.1007/BF02703109

Lewis VA, Hynes GM, Zheng D, Saibil H, Willison K. 1992. T-complex polypeptide- 1 is a subunit of a heteromeric particle in the eukaryotic cytosol. Nature 358: 249-252. doi:10.1038/358249a0

Liu J, DeFranco DB. 1999. Chromatin recycling of glucocorticoid receptors: Implications for multiple roles of heat shock protein 90. Mol Endocrinol 13: 355-365. doi:10.1210/mend.13.3.0258

Liu JS, Kuo SR, Makhov AM, Cyr DM, Griffith JD, Broker TR, Chow LT. 1998. Human Hsp70 and Hsp40 chaperone proteins facilitate human papillomavirus-11 E1 protein binding to the origin and stimulate cell-free DNA replication. J Biol Chem 273: 30704-30712. doi:10.1074/ jbc.273.46.30704

Mayer MP, Bukau B. 2005. Hsp70 chaperones: Cellular functions and molecular mechanism. Cell Mol Life Sci 62: 670-684. doi:10.1007/s00018-004-4464-6

McClellan AJ, Xia Y, Deutschbauer AM, Davis RW, Gerstein M, Frydman J. 2007. Diverse cellular functions of the Hsp90 molecular chaperone uncovered using systems approaches. Cell 131: 121-135. doi:10.1016/j.cell.2007. 07.036

Mendez F, Kozin E, Bases R. 2003. Heat shock protein 70 stimulation of the deoxyribonucleic acid base excision repair enzyme polymerase $\beta$. Cell Stress Chaperones 8: 153-161.

Metuzals J, Robitaille Y, Houghton S, Gauthier S, Leblanc R. 1988. Paired helical filaments and the cytoplasmic- 
nuclear interface in Alzheimer's disease. J Neurocytol 17: 827-833. doi:10.1007/BF01216709

Milarski KL, Welch WJ, Morimoto RI. 1989. Cell cycle-dependent association of HSP70 with specific cellular proteins. J Cell Biol 108: 413-423. doi:10.1083/jcb.108.2.413

Millson SH, Truman AW, King V, Prodromou C, Pearl LH, Piper PW. 2005. A two-hybrid screen of the yeast proteome for Hsp90 interactors uncovers a novel Hsp90 chaperone requirement in the activity of a stress-activated mitogen-activated protein kinase, Slt2p (Mpk1p). Eukaryot Cell 4: 849-860. doi:10.1128/EC.4.5.849-860.2005

Miyoshi T, Takeuchi A, Siomi H, Siomi MC. 2010. A direct role for Hsp90 in pre-RISC formation in Drosophila. Nat Struct Mol Biol 17: 1024-1026. doi:10.1038/nsmb.1875

Morcillo G, Diez JL, Carbajal ME, Tanguay RM. 1993. HSP90 associates with specific heat shock puffs $(h s r \omega)$ in polytene chromosomes of Drosophila and Chironomus. Chromosoma 102: 648-659. doi:10.1007/BF00352313

Mueller F, Stasevich TJ, Mazza D, McNally JG. 2013. Quantifying transcription factor kinetics: at work or at play? Crit Rev Biochem Mol Biol 48: 492-514. doi:10.3109/ 10409238.2013.833891

Mukherjee K, Nagai H, Shimamoto N, Chatterji D. 1999. GroEL is involved in activation of Escherichia coli RNA polymerase devoid of the omega subunit in vivo. Eur $J$ Biochem 266: 228-235. doi:10.1046/j.1432-1327.1999. 00848. $\mathrm{x}$

Nielsen SV, Poulsen EG, Rebula CA, Hartmann-Petersen R. 2014. Protein quality control in the nucleus. Biomolecules 4: 646-661. doi:10.3390/biom4030646

Okazaki K, Kato H, Iida T, Shinmyozu K, Nakayama JI, Murakami Y, Urano T. 2018. RNAi-dependent heterochromatin assembly in fission yeast Schizosaccharomyces pombe requires heat-shock molecular chaperones Hsp90 and Mas5. Epigenetics Chromatin 11: 26. doi:10.1186/ s13072-018-0199-8

Paek KH, Walker GC. 1987. Escherichia coli dnaK null mutants are inviable at high temperature. J Bacteriol 169: 283-290. doi:10.1128/jb.169.1.283-290.1987

Park SH, Kukushkin Y, Gupta R, Chen T, Konagai A, Hipp MS, Hayer-Hartl M, Hartl FU. 2013. PolyQ proteins interfere with nuclear degradation of cytosolic proteins by sequestering the Sis1p chaperone. Cell 154: 134-145. doi:10.1016/j.cell.2013.06.003

Pelham HRB. 1984. Hsp70 accelerates the recovery of nucleolar morphology after heat shock. EMBO J 3: 3095-3100. doi:10.1002/j.1460-2075.1984.tb02264.x

Pennisi R, Antoccia A, Leone S, Ascenzi P, di Masi A. 2017. Hsp90 $\alpha$ regulates ATM and NBN functions in sensing and repair of DNA double-strand breaks. FEBS J 284: 2378-2395. doi:10.1111/febs.14145

Petit MA, Bedale W, Osipiuk J, Lu C, Rajagopalant M, McInerney P, Goodman MF, Echols H. 1994. Sequential folding of UmuC by the Hsp70 and Hsp60 chaperone complexes of Escherichia coli. J Biol Chem 269: 2382423829.

Picard D, Khursheed B, Garabedian MJ, Fortin MG, Lindquist S, Yamamoto KR. 1990. Reduced levels of hsp90 compromise steroid receptor action in vivo. Nature 348: 166-168. doi:10.1038/348166a0
Powers ET, Morimoto RI, Dillin A, Kelly JW, Balch WE. 2009. Biological and chemical approaches to diseases of proteostasis deficiency. Annu Rev Biochem 78: 959-991. doi:10.1146/annurev.biochem.052308.114844

Prasad R, Xu C, Ng DTW. 2018. Hsp40/70/110 chaperones adapt nuclear protein quality control to serve cytosolic clients. J Cell Biol 217: 2019-2032. doi:10.1083/jcb. 201706091

Prasanth KV, Rajendra TK, Lal AK, Lakhotia SC. 2000. Omega speckles-A novel class of nuclear speckles containing hnRNPs associated with noncoding $h s r \omega$ RNA in Drosophila. J Cell Sci 113: 3485-3497.

Pratt WB, Toft DO. 1997. Steroid receptor interactions with heat shock protein and immunophilin chaperones. En docr Rev 18: 306-360.

Quanz M, Herbette A, Sayarath M, De Koning L, Dubois T, Sun JS, Dutreix M. 2012. Heat shock protein $90 \alpha$ (Hsp90 $\alpha$ ) is phosphorylated in response to DNA damage and accumulates in repair foci. J Biol Chem 287: 88038815. doi:10.1074/jbc.M111.320887

Ritossa F. 1962. A new puffing pattern induced by temperature shock and DNP in Drosophila. Experientia 18: 571573. doi:10.1007/BF02172188

Roobol A, Carden MJ. 1999. Subunits of the eukaryotic cytosolic chaperonin CCT do not always behave as components of a uniform hetero-oligomeric particle. Eur J Cell Biol 78: 21-32. doi:10.1016/S0171-9335(99)80004-1

Russell JS, Burgan W, Oswald KA, Camphausen K, Tofilon PJ. 2003. Enhanced cell killing induced by the combination of radiation and the heat shock protein 90 inhibitor 17-allylamino-17-demethoxygeldanamycin: A multitarget approach to radiosensitization. Clin Cancer Res 9: 3749-3755.

Sabbah M, Radanyi C, Redeuilh G, Baulieu EE. 1996. The 90 $\mathrm{kDa}$ heat-shock protein (hsp90) modulates the binding of the oestrogen receptor to its cognate DNA. Biochem J 314: 205-213. doi:10.1042/bj3140205

Saito H, Uchida H. 1978. Organization and expression of the dnaJ and dnaK genes of Escherichia coli K12. Mol Gen Genet 164: 1-8. doi:10.1007/BF00267592

Sakakibara Y. 1988. The dnaK gene of Escherichia coli functions in initiation of chromosome replication. J Bacteriol 170: 972-979. doi:10.1128/jb.170.2.972-979.1988

Sanchez ER, Toft DO, Schlesinger MJ, Pratt WB. 1985. Evidence that the $90-\mathrm{kDa}$ phosphoprotein associated with the untransformed L-cell glucocorticoid receptor is a murine heat shock protein. J Biol Chem 260: 12398-12401.

Sawarkar R, Sievers C, Paro R. 2012. Hsp90 globally targets paused RNA polymerase to regulate gene expression in response to environmental stimuli. Cell 149: 807-818. doi:10.1016/j.cell.2012.02.061

Schopf FH, Biebl MM, Buchner J. 2017. The HSP90 chaperone machinery. Nat Rev Mol Cell Biol 18: 345-360. doi:10.1038/nrm.2017.20

Shevchenko A, Schaft D, Roguev A, Pijnappel WWMP, Stewart AF, Shevchenko A. 2002. Deciphering protein complexes and protein interaction networks by tandem affinity purification and mass spectrometry. Mol Cell Proteomics 1: 204-212. doi:10.1074/mcp.M200005-MCP200

Shevchenko A, Roguev A, Schaft D, Buchanan L, Habermann B, Sakalar C, Thomas H, Krogan NJ, Shevchenko 


\section{Z. Gvozdenov et al.}

A, Stewart AF. 2008. Chromatin central: Towards the comparative proteome by accurate mapping of the yeast proteomic environment. Genome Biol 9: R167. doi:10. 1186/gb-2008-9-11-r167

Shi Y, Mosser DD, Morimoto RI. 1998. Molecular chaperones as HSF1-specific transcriptional repressors. Genes Dev 12: 654-666. doi:10.1101/gad.12.5.654

Skelly S, Fu CF, Dalie B, Redfield B, Coleman T, Brot N, Weissbach H. 1988. Antibody to $\sigma^{32}$ cross-reacts with DnaK: association of DnaK protein with Escherichia coli RNA polymerase. Proc Natl Acad Sci 85: 5497-5501. doi:10.1073/pnas.85.15.5497

Skowyra D, Georgopoulos C, Zylicz M. 1990. The E. coli dnaK gene product, the hsp70 homolog, can reactivate heat-inactivated RNA polymerase in an ATP hydrolysisdependent manner. Cell 62: 939-944. doi:10.1016/00928674(90)90268-J

Souès S, Kann ML, Fouquet JP, Melki R. 2003. The cytosolic chaperonin CCT associates to cytoplasmic microtubular structures during mammalian spermiogenesis and to heterochromatin in germline and somatic cells. Exp Cell Res 288: 363-373. doi:10.1016/S0014-4827(03)00248-9

Spradling A, Pardue ML, Penman S. 1977. Messenger RNA in heat-shocked Drosophila cells. J Mol Biol 109: 559-587. doi:10.1016/S0022-2836(77)80091-0

Sternberg N. 1973. Properties of a mutant of Escherichia coli defective in bacteriophage $\lambda$ head formation (groE). II The propagation of phage $\lambda$. J Mol Biol 76: 25-44. doi:10.1016/0022-2836(73)90079-X

Suhane T, Laskar S, Advani S, Roy N, Varunan S, Bhattacharyya D, Bhattacharyya S, Bhattacharyya MK. 2015. Both the charged linker region and ATPase domain of Hsp90 are essential for Rad51-dependent DNA repair. Eukaryotic Cell 14: 64-77. doi:10.1128/EC.00159-14

Tanguy Le Gac N, Boehmer PE. 2002. Activation of the herpes simplex virus type-1 origin-binding protein (UL9) by heat shock proteins. J Biol Chem 277: 5660 5666. doi:10.1074/jbc.M108316200

Tapia H, Morano KA. 2010. Hsp90 nuclear accumulation in quiescence is linked to chaperone function and spore development in yeast. Mol Biol Cell 21: 63-72. doi:10 1091/mbc.e09-05-0376

Tariq M, Nussbaumer U, Chen Y, Beisel C, Paro R. 2009. Trithorax requires $\mathrm{Hsp} 90$ for maintenance of active chromatin at sites of gene expression. Proc Natl Acad Sci 106: 1157-1162. doi:10.1073/pnas.0809669106

Tilly K, Murialdo H, Georgopoulos C. 1981. Identification of a second Escherichia coli groE gene whose product is necessary for bacteriophage morphogenesis. Proc Natl Acad Sci 78: 1629-1633. doi:10.1073/pnas.78.3.1629

Tissiéres A, Mitchell HK, Tracy UM. 1974. Protein synthesis in salivary glands of Drosophila melanogaster: Relation to chromosome puffs. J Mol Biol 84: 389-398. doi:10.1016/ 0022-2836(74)90447-1

Toogun OA, DeZwaan DC, Freeman BC. 2008. The Hsp90 molecular chaperone modulates multiple telomerase ac- tivities. Mol Cell Biol 28: 457-467. doi:10.1128/MCB. 01417-07

Van Bergen en Henegouwen PMP, Berbers G, Linnemans WAM, Van Wijk R. 1987. Subcellular localization of the 84,000 dalton heat-shock protein in mouse neuroblastoma cells: Evidence for a cytoplasmic and nuclear location. Eur J Cell Biol 43: 469-478.

Velazquez JM, Lindquist S. 1984. Hsp70: Nuclear concentration during environmental stress and cytoplasmic storage during recovery. Cell 36: 655-662. doi:10.1016/00928674(84)90345-3

Wada M, Itikawa H. 1984. Participation of Escherichia coli $\mathrm{K}-12$ groE gene products in the synthesis of cellular DNA and RNA. J Bacteriol 157: 694-696.

Wellinger RJ, Zakian VA. 2012. Everything you ever wanted to know about Saccharomyces cerevisiae telomeres: Beginning to end. Genetics 191: 1073-1105. doi:10.1534/ genetics.111.137851

Wickner S, Hoskins J, McKenney K. 1991. Function of DnaJ and DnaK as chaperones in origin-specific DNA binding by RepA. Nature 350: 165-167. doi:10.1038/350165a0

Wilkinson CR, Wallace M, Morphew M, Perry P, Allshire R, Javerzat JP, McIntosh JR, Gordon C. 1998. Localization of the $26 \mathrm{~S}$ proteasome during mitosis and meiosis in fission yeast. EMBO J 17: 6465-6476.

Yochem J, Uchida H, Sunshine M, Saito H, Georgopoulos C, Feiss M. 1978. Genetic analysis of two genes, dnaJ and dnaK, necessary for Escherichia coli and bacteriophage $\lambda$ DNA replication. Mol Gen Genet 164: 9-14. doi:10.1007/ BF00267593

Yost HJ, Lindquist S. 1986. RNA splicing is interrupted by heat shock and is rescued by heat shock protein synthesis. Cell 45: 185-193. doi:10.1016/0092-8674(86)90382-X

Zhao R, Davey M, Hsu YC, Kaplanek P, Tong A, Parsons AB, Krogan N, Cagney G, Mai D, Greenblatt J, et al. 2005. Navigating the chaperone network: An integrative map of physical and genetic interactions mediated by the hsp90 chaperone. Cell 120: 715-727. doi:10.1016/j. cell.2004.12.024

Ziemienowicz A, Skowyra D, Zeilstra-Ryalls J, Fayet O, Georgopoulos C, Zylicz M. 1993. Both the Escherichia coli chaperone systems, GroEL/GroES and DnaK/DnaJ/ GrpE, can reactivate heat-treated RNA polymerase. J Biol Chem 268: 25425-25431.

Zou Y, Crowley DJ, Van Houten B. 1998. Involvement of molecular chaperonins in nucleotide excision repair. $J$ Biol Chem 273: 12887-12892. doi:10.1074/jbc.273.21. 12887

Zweig M, Cummings DJ. 1973. Cleavage of head and tail proteins during bacteriophage T5 assembly: Selective host involvement in the cleavage of a tail protein. $J \mathrm{Mol}$ Biol 80: 505-518. doi:10.1016/0022-2836(73)90418-X

Zylicz M. 1993. The Escherichia coli chaperones involved in DNA replication. Philos Trans R Soc Lond B Biol Sci 339: 271-278. doi:10.1098/rstb.1993.0025 


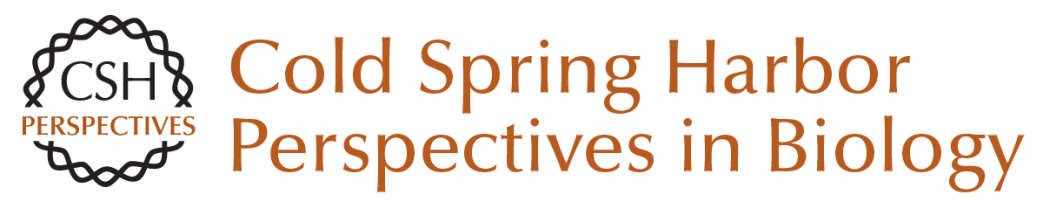

\title{
The Nuclear and DNA-Associated Molecular Chaperone Network
}

\author{
Zlata Gvozdenov, Janhavi Kolhe and Brian C. Freeman \\ Cold Spring Harb Perspect Biol 2019; doi: 10.1101/cshperspect.a034009 originally published online \\ February 11, 2019
}

\section{Subject Collection Protein Homeostasis}

Proteome-Scale Mapping of Perturbed

Proteostasis in Living Cells

Isabel Lam, Erinc Hallacli and Vikram Khurana

Pharmacologic Approaches for Adapting Proteostasis in the Secretory Pathway to

Ameliorate Protein Conformational Diseases Jeffery W. Kelly

Cell-Nonautonomous Regulation of Proteostasis in Aging and Disease

Richard I. Morimoto

The Autophagy Lysosomal Pathway and

Neurodegeneration

Steven Finkbeiner

Functional Modules of the Proteostasis Network Gopal G. Jayaraj, Mark S. Hipp and F. Ulrich Hartl

Protein Solubility Predictions Using the CamSol Method in the Study of Protein Homeostasis Pietro Sormanni and Michele Vendruscolo

Recognition and Degradation of Mislocalized

Proteins in Health and Disease

Ramanujan S. Hegde and Eszter Zavodszky

The Nuclear and DNA-Associated Molecular Chaperone Network

Zlata Gvozdenov, Janhavi Kolhe and Brian C. Freeman
The Amyloid Phenomenon and Its Significance in Biology and Medicine

Christopher M. Dobson, Tuomas P.J. Knowles and Michele Vendruscolo

A Chemical Biology Approach to the Chaperome

in Cancer--HSP9O and Beyond

Tony Taldone, Tai Wang, Anna Rodina, et al.

Proteostasis in Viral Infection: Unfolding the Complex Virus-Chaperone Interplay Ranen Aviner and Judith Frydman

The Proteasome and Its Network: Engineering for Adaptability Daniel Finley and Miguel A. Prado

Functional Amyloids Daniel Otzen and Roland Riek

Chaperone Interactions at the Ribosome Elke Deuerling, Martin Gamerdinger and Stefan G. Kreft

Mechanisms of Small Heat Shock Proteins Maria K. Janowska, Hannah E.R. Baughman, Christopher N. Woods, et al.

Structure, Function, and Regulation of the Hsp90 Machinery

Maximilian M. Biebl and Johannes Buchner

For additional articles in this collection, see http://cshperspectives.cshlp.org/cgi/collection/

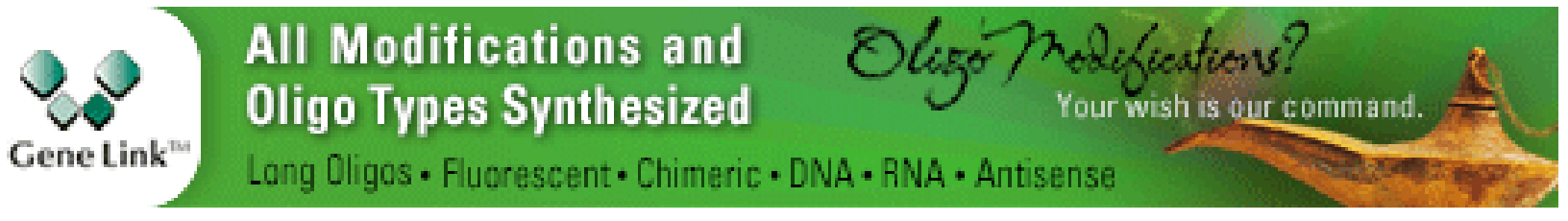


For additional articles in this collection, see http://cshperspectives.cshlp.org/cgi/collection/

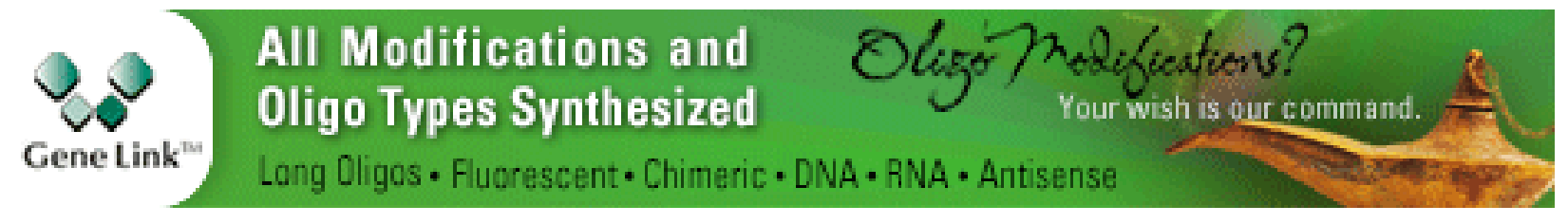

Copyright @ 2019 Cold Spring Harbor Laboratory Press; all rights reserved 